of iron, no firm conclusions can be drawn. Until they can be, it seems prudent to prescribe iron only for iron deficiency and during pregnancy.

Queensland Institute of Medical Research,

Brisbane,

Queensland 4029, Australia

1 Sullivan JL. Iron and the sex difference in heart disease risk. Lancet 1981;i:1293-4.

2 Sullivan IL. The iron paradigm of ischemic heart disease. Am Hean $f$ 1989;117:1177-88.

3 Lauffer RB. Iron stores and the international variation in mortality from coronary artery disease. Med Hypotheses 1990;35:96-102.

4 Salonen JT, Nyyssőnen K, Korpela H, Tuomilehto J, Seppănen R, Salonen R. High stored iron levels are associated with excess risk of myocardial infarction in eastern Finnish men. Circulation 1992;86:803-11
5 Leggett BA, Brown NN, Bryant SJ, Duplock L, Powell LW, Halliday JW. Factors affecting the concentrations of ferritin in serum in a healthy Australian population. Clin Chem 1990;36: $1350-5$

6 Steinberg D, Parthasarathy S, Carew TE, Khoo JC, Witztum JL. Beyond cholesterol. Modifications of low-density lipoprotein that increase its atherogenicity. $N$ Engl f Med 1989;320:915-24.

7 Salonen JT, Ylä-Herttuala S, Yamamoto R, Butler S, Korpela H, Salonen R, et al. Autoantibody against oxidised LDL and progression of carotid atherosclerosis. Lancet 1992;339:883-7.

8 Carew TE, Schwenke DC, Steinberg D. Antiatherogenic effect of probucol unrelated to its hypocholesterolemic effect: evidence that antioxidants in vivo can selectively inhibit low density lipoprotein degradation in macrophage-rich fatty streaks and slow the progression of atherosclerosis in the Watanabe heritable hyperlipidemic rabbit. Proc Natl Acad Sci USA 1987;84: 7725-9.

9 Riemersma RA, Wood DA, MacIntyre CCA, Elton RA, Gey KF, Oliver MF. Risk of angin pectoris and plasma concentrations of vitamin A, C, and E and carotene. Lancet 1991;337:1-5.

10 Halliwell B. Current status review: free radicals, reactive oxygen species and human disease: a critical evaluation with special reference to atherosclerosis. British foumal of Experimental Pathology 1989;70:737-57.

11 Williams RE, Zweier JL, Flaherty JT. Treatment with deferoxamine during ischemia improves functional and metabolic recovery and reduces reperfusion-induced oxygen radical generation in rabbit hearts. Circulation 1991;83:1006-14.

12 Bradbear RA, Bain C, Siskind V, Schofield FD, Webb S, Axelsen E, et al. Cohort study of internal malignancy in genetic hemochromatosis and other chronic nonalcoholic liver diseases. $\mathcal{f} \mathrm{Nat}$ Cancer Inst 1985;75:81-4.

13 Powell LW, Halliday JW, Wilson A, Siskind V, Bain C, Bradbear RA. Proceedings of the 4th international conference on haemochromatosis and clinical problems in iron metabolism. Israel, 1993.

\title{
Should purchasers pay for psychotherapy?
}

\section{All therapies must prove their worth; some have found this easier than others}

Psychotherapy is a nebulous term referring to a seemingly infinite variety of "talking cures" of differing intensity, duration, and theoretical sophistication. The new rigours of the purchaser-provider split mean that all such treatments will now be subject to the same cost-benefit analyses that have restricted the range of psychotherapy funded by private health insurance. Psychotherapies that controlled trials have shown to be effective and safe and to offer good value for money will be in a stronger position to argue their case in the health marketplace. But among psychotherapists attitudes to cost-benefit analysis are polarised, and information on the utility of the interventions is uneven in quality.

The psychotherapy that has adopted the market approach par excellence is behaviour therapy. The practice of graded exposure to phobic stimuli incorporates the routine measurement of symptoms during treatment and the recording of hours of therapy. Cost-benefit information is thus readily available. Behaviour therapy has proved itself an effective and economical method of treating phobic, obsessive compulsive, sexual, and habit disorders, ${ }^{1}$ providing lasting reductions in symptoms together with measurable economic benefits to patients, families, and the health service. ${ }^{2}$ Employing trained nurse therapists could further reduce its costs. ${ }^{3}$

Cognitive behavioural therapy combines some of the principles of behaviour therapy with a systematic analysis and challenging of the thoughts and beliefs that underlie mood disturbance, low self esteem, or dysfunctional behaviour. This therapy has also been subject to rigorous comparisons with other forms of brief psychotherapy and pharmacotherapy. The results suggest that it is effective for mild or moderate depression, ${ }^{4}$ and may be as effective as, if not better than, antidepressant drugs in preventing relapse. ${ }^{56}$ It has also been used successfully in various neurotic disorders, ${ }^{7}$ such as bulimia nervosa. ${ }^{8}$ Treatment can be given by psychiatrists, psychologists, or nurses (usually supervised by a senior psychologist or psychiatrist).

The role of the dynamic psychotherapies within the new NHS presents the most difficulty for purchasers and managers. The methodological difficulties in assessing the effectiveness of intensive long term analytic therapies, such as defining the nature of treatment and devising control treatments, means that there is a dearth of controlled studies.
Some therapists argue that the aim of this type of therapy is to promote change that is not amenable to simple measurement. These arguments are unlikely to impress purchasers or managers, but psychodynamic psychotherapists in the NHS are finally beginning to provide more convincing arguments. ${ }^{9}$

Although patients improve over the course of long term psychotherapy, ${ }^{10}$ Andrews has noted that, without controlled trials, it is impossible to decide how much improvement is due to the specific effects of treatment and how much is due to a placebo effect or the passage of time. ${ }^{11}$ Andrews also draws attention to the considerable expense, and occasional adverse effects, of long term psychotherapy. An Australian survey found that therapists spent an average of 330 hours with their patients, although they failed to define the indications for such therapy. ${ }^{12}$ The length of therapy, and the shortage of therapists, meant that only a small fraction of those with mental health problems could be treated. Purchasers will justifiably be wary of funding such an inequitable service.

Dynamic psychotherapists may have to consider new methods of working, and new client groups, if they are to meet the challenge of the market. One rarely explored avenue lies in the health of the NHS workforce-an explicit target of The Health of the Nation. NHS psychotherapists must also move beyond the traditional clients of their colleagues in private practice. They may have a role in the management of personality disorders, victims of childhood abuse, and those with abnormal illness behaviour. They must take note that the selection of relatively homogeneous diagnostic groups for studies of the brief psychotherapies has been an important step in assessing efficacy and defining clinical indications in the public health care system. Without a clear target group, and without evidence of efficacy, the long term therapies are vulnerable when it comes to decisions about resources.

Several brief psychodynamic therapies have been developed, which address some of these criticisms. A metaanalysis of 11 studies that used treatment manuals or similar ways of ensuring adherence to treatment concluded that treated patients did significantly better than controls taken from the waiting list, ${ }^{13}$ but the effects of brief psychodynamic therapies differed little from those of placebo, self-help, and 
counselling and were marginally worse than those of other psychiatric treatments. In some well designed controlled studies that focused on discrete disorders such as bulimia nervosa, however, outcomes were similar in patients treated with cognitive behavioural therapy or brief psychodynamic therapies. We remain relatively ignorant about how the brief psychotherapies work and how they can be best delivered. Certainly, the evidence is not available to allow purchasers to decide which brief therapies the health service should offer.

Purchasers must also be aware of the rapid spread of counselling services, which now dominate the mental health services provided in primary care. This growth has been seemingly unhampered by the absence of a satisfactory definition of what is on offer as well as a lack of controlled evaluations. A recent survey showed that a high proportion of counsellors lacked qualifications and were working without adequate supervision. ${ }^{14}$

A further challenge for those purchasing or providing psychotherapy services is to avoid limiting their vision to the traditional users of mental health services. It is well established that psychological disorders are common outside these settings. For example, health care economists at Kaiser Permanente wrote that, if unchecked, the unmet mental health needs of patients in general hospitals might bankrupt the American health care system..$^{15}$ The general hospital is frequently referred to as "America's second mental health service." Somatisation disorders, chronic fatigue, myalgia, and irritable syndromes, as well as the psychological problems of physical illness, account for an immense burden of morbidity to sufferers and cost to the NHS. ${ }^{16}$ Yet these patients are frequently overlooked by the providers of acute medical care and remain invisible to the customary providers of mental health services. This is regrettable, as both behavioural and cognitive behavioural approaches are rapidly proving their effectiveness for these groups ${ }^{17}$ and, ironically, one of the most convincing demonstrations of the efficacy of dynamic psychotherapy took place in a general hospital. ${ }^{18}$

Some patients do not respond to the brief therapies or, owing to the long duration or severity of their disorders, are deemed unsuitable for these interventions. Psychotherapists may be the only clinicians who can help these difficult patients, but to continue to do so they must justify the cost of treatment, not only in terms of improved health of their patients but also in terms of decreased costs to the NHS. They must also overcome the problem of engaging certain reluctant client groups, such as young people and those of lower social class. ${ }^{19}$

The new marketplace will have important consequences for both providers and purchasers of psychotherapy services. Purchasers must now ensure the availability of the newer brief psychotherapies of proved value in neurotic disorders. They may also need to resist the demand for more counselling services until better evidence of efficacy and safety is available. Finally, they need to take the leading role in ensuring that access to psychotherapy moves beyond the traditional clients of mental health services.

TOM FAHY Lecturer

SIMON WESSELY Senior lecturer

Academic Department of Psychological Medicine,

King's College School of Medicine and Dentistry and Institute of Psychiatry,

London SE5 9RS

Marks I. Fears, phobias and rituals. New York: Oxford University Press, 1987.

2 Ginsberg G, Marks I. Costs and benefits of behavioural psychotherapy: a pilot study of neurotics treated by nurse therapists. Psychol Med 1977;7:685-700.

(1985;290:1181-4

4 Beck AT, Hollon SD, Young JE, Bedrosian RC, Budenz D. Treatment of depression with cognitive therapy and amitriptyline. Arch Gen Psychiatry 1985;42:142-8.

5 Blackburn IM, Eunson KM, Bishop S. A two-year naturalistic follow-up of depressed patients treated with cognitive therapy, pharmacotherapy and a combination of both. I Affect Dis 1986;10:67-75.

6 University of Leeds. The treatment of depression in primary care. Effective Health Care Bulletin No 5 1993: March.

7 Hawton K, Salkovskis P, Kirk J, Clark D. Cognitive behaviour therapy for psychiatric patients: a practical guide. Oxford: Oxford University Press, 1989.

8 Fairburn C, Jones R, Peveler R, Hope R, O'Connor M. Psychotherapy and bulimia nervosa: Longer-term effects of interpersonal psychotherapy, behavior therapy and cognitive behavio therapy. Arch Gen Psychiatry 1993;50:419-28.

9 Milton J. Presenting the case for psychoanalytic psychotherapy services. An annotated bibliography. Discussion document. London: Association for Psychoanalytic Psychotherapy in the NHS and Tavistock Clinic, 1992.

10 Clementel-Jones C, Malan D, Trauer T. A retrospective follow-up of 84 individual psychoanalytic psychotherapy. Outcome and predictive factors. British foumal of Psychotherapy 1990;6:363-74

1 Andrews G. The essential psychotherapies. Br f Psychiatry 1993;162:447-51.

12 Andrews G, Hadzi-Pavlovic D. The work of Australian psychiatrists, circa 1986. Aust NZ Psychiatry 1988;22:153-65.

13 Crits-Christoph P. The efficacy of brief dynamic psychotherapy: a meta-analysis. Am $\mathcal{F}$ Psychiatry 1992;149:151-8.

14 Sibbald B, Addington-Hull J, Brennerman D, Freeling P. Counselling in English and Welsh general practices: their nature and distribution. BMF 1993;306:29-33.

15 Cummings N, VandenBos G. The twenty years Kaiser-Permanente experience with psychotherapy and medical utilization: implications for national health policy and national health insurance. Health Policy Quarterly 1981;1:159-75.

16 Fink P. Surgery and medical treatment in persistent somatizing patients. $f$ Psychosom Res 1992;36:439-47.

17 Sharpe M, Peveler R, Mayou R. The psychological treatment of patients with functional somatic symptoms: a practical guide. I Psychosom Res 1992;36:55-29.

18 Guthrie E, Creed F, Dawson D, Tomenson B. A controlled trial of psychological treatment for the irritable bowel syndrome. Gastroenterology 1991;100:450-7.

19 Scott A, Freeman C. Edinburgh primary care depression study: treatment outcome, patient satisfaction and cost after 16 weeks. BMf 1992;304:883-7.

\title{
From specialist care to self directed treatment
}

\author{
Empower the patient and spare the clinician
}

We can no longer escape the conclusion that the number of patients who can be helped by treatment that depends on technology is limited by constraints on resources. This applies as much to psychological as to physical treatments. The specialist knowledge, skills, and time required for one to one psychotherapy, for example, are also limited resources. A possible way to resolve this dilemma may be for some patients to use self directed treatment manuals, thereby saving scarce resources for those who need them most. An additional benefit of this approach, in which skill is shared with the users of health care, is that it enables patients to become more actively involved in their own health care. ${ }^{1}$ Arguments that such methods increase users' mastery and self esteem make a virtue out of necessity. The important questions are whether self directed treatment works and for which conditions.

Despite the overwhelming number of books on health problems that have been written specifically for the public, relatively few actually teach users how to deal with their problems. Even fewer of these texts have been tested against other interventions. ${ }^{2}$

One approach of self directed treatment has been to educate people about harmful lifestyles and to teach them how to minimise the ensuing risk to health. Manuals to reduce smoking seem to be a weak intervention when used alone, ${ }^{3}$ unless motivation is increased. ${ }^{4}$ Pregnancy may provide such 